\title{
Porównanie szumu Barkhausena i własnego magnetycznego pola rozproszenia w odkształconych plastycznie próbkach ze stali S235 i P265GH
}

\author{
A comparison of Barkhausen noise and the residual \\ magnetic field in plastically deformed samples \\ made of S235 and P265GH steel
}

\section{Streszczenie}

Zmiany stanu wytężenia, struktury i temperatury tworzywa ferromagnetycznego wpływają na zmiany stanu równowagi energetycznej na poziomie atomowym, skutkując zmianami makroskopowych właściwości magnetycznych i elektrycznych. W artykule przedstawiono wyniki pomiarów szumu Barkhausena i własnego magnetycznego pola rozproszenia WMPR w próbkach odkształconych plastycznie. Porównano rozkłady wielkości ilościowo opisujących szum Barkhausena i WMPR. Stwierdzono, że zróżnicowanie stopnia deformacji plastycznej dobrze oddają energia szumu Barkhausena EBN, liczba zliczeń NBN oraz gradienty składowych WMPR. Czułość tych sygnałów diagnostycznych jest zbliżona. Możliwe jest opracowanie ilościowych relacji diagnostycznych służących do oceny stopnia deformacji na podstawie ww. wielkości. Opracowanie rzetelnych relacji diagnostycznych wymaga rozwiązania szeregu problemów metrologicznych. Są one związane z wpływem kształtu i wielkości elementu, stanem warstwy wierzchniej, struktury oraz ogólnego stanu namagnesowania.

\section{Wprowadzenie i cel badań}

Zmiany stanu wytężenia, struktury i temperatury tworzywa ferromagnetycznego wpływają na zmiany stanu równowagi energetycznej na poziomie atomowym,

Dr inż. Maciej Roskosz, inż. Krzysztof Fryczowski - Politechnika Śląska, Gliwice.
Abstract

Changes in the stress state, structure and temperature of a ferromagnetic material result in changes in the balance of energy at the atomic level, causing variations in macroscopic magnetic and electrical properties. The paper presents the results of measurements of Barkhausen noise and of the residual magnetic field (RMF) in plastically deformed samples. A comparison is made of the distributions of values which describe Barkhausen noise and the RMF quantitatively. It is found that the differences in the degree of plastic deformation are well reflected by the energy of Barkhausen noise EBN, the number of counts NBN and the gradients of the RMF components. The sensitivity of these diagnostic signals is similar. It is possible to develop quantitative diagnostic relations that could be used to assess the degree of plastic deformation based on the values mentioned above. The development of reliable diagnostic relationships requires a solution to a series of metrological problems which are related to the impact of the shape and size of the component, to the state of the surface layer, the structure and to the overall state of magnetisation.

powoduje zmiany makroskopowe właściwości magnetycznych i elektrycznych $[1 \div 5]$. Wykorzystanie efektu Barkhausena oraz własnego magnetycznego pola rozproszenia WMPR jako sygnałów diagnostycznych znajduje coraz szersze zastosowanie w szeroko pojętej ocenie stanu [6 $\div 11]$. Z powodu braku ogólnie przyjętych standardów (norm), nieuznawania metod wykorzystujących te sygnały przez jednostki notyfikowane, muszą być one traktowane jako dodatkowe (uzupełniające) metody badań. 
Prowadzone w wielu ośrodkach badania mają na celu wykazanie możliwości i ograniczeń wykorzystania efektu Barkhausena i WMPR w diagnostyce [6 $\div 11]$. Celem prezentowanych badań było porównanie rozkładów wielkości ilościowo opisujących szum Barkhausena i WMPR w próbkach odkształconych plastycznie z zauważalnym lokalnym przewężeniem - szyjka. Przeanalizowano również możliwość identyfikacji obszarów odkształconych plastycznie oraz oceny stopnia trwałej deformacji.

\section{Metodyka badań}

Badano próbki płytowe wykonane ze stali S235 i P265GH. Geometrię próbek nieodkształconych plastycznie pokazano schematycznie na rysunku 1 . Początkowe struktury metalograficzne pokazano na rysunku 2 dla stali S235 oraz na rysunku 3 dla stali P265GH. W tablicy I zestawiono składy chemiczne badanych stali. Próbki poddano procesowi rozciągania, który przerywano w momencie pojawienia się lokalnego przewężenia - szyjki. Do pomiarów WMPR wykorzystywano magnetometr TSC-1M-4 z głowica pomiarowa TSC-2M dostarczony przez Energodiagnostika Co. Ltd Moscow. Aparatura pomiarowa została wykalibrowana w polu magnetycznym Ziemi do założonej wartości $40 \mathrm{~A} / \mathrm{m}$. Pomiary natężenia pola magnetycznego wykonywano wzdłuż linii pomiarowej, której początkowa długość wynosiła $200 \mathrm{~mm}$ (rys. 1).

Mierzono trzy składowe WMPR na powierzchni próbki (rys. 1):

- $\mathrm{H}_{\mathrm{T}, \mathrm{X}}$ - składowa styczna mierzona w kierunku prostopadłym do kierunku rozciagania,

- $\mathrm{H}_{\mathrm{TY}}$ - składowa styczna mierzona w kierunku równoległym do kierunku rozciągania,

- $\mathrm{H}_{\mathrm{N}, \mathrm{Z}}$ - składowa normalna.

Pomiary szumu Barkhausena prowadzono za pomocą urządzenia MEB4-C dostarczonego przez firmę Mag-Lab z Gdańska z wykorzystaniem sondy stykowej (cewka magnesująca i pomiarowa w jednej obudowie). Pomiary szumu Barkhausena prowadzono w wybranych punktach leżących na linii pomiarowej. W każdym punkcie dokonywano dwóch pomiarów, dla dwóch kierunków magnesowania:

- kierunku $X$ - prostopadłego do osi obciążenia,

- kierunku Y - współosiowego z obciążeniem.

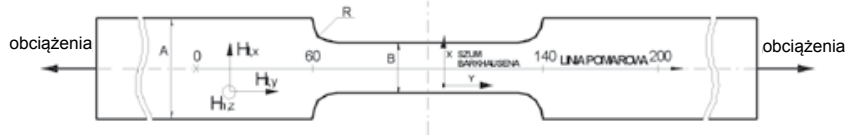

Rys. 1. Próbka do badań

Fig. 1. Sample for tests

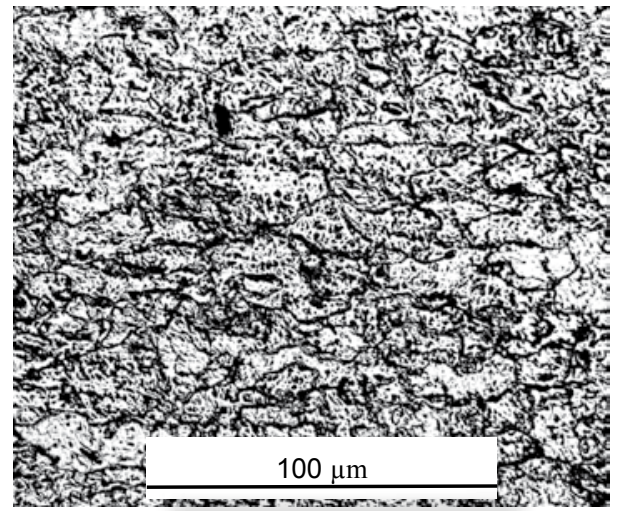

Rys. 2. Stal S235 - struktura ferrytu z niewielkimi obszarami drobnego poślizgu i drobnymi skoagulowanymi węglikami wewnątrz ziaren ferrytu. Ziarna wydłużone w kierunku walcowania. Zgład metalograficzny trawiony nitalem. Pow. 1000x

Fig. 2. S235 steel - ferritic structure with small areas of small slip and fine carbides within the grains of ferrite. Grains elongated in the rolling direction, Metallographic cross-section etched by Nital. Magn. 1000x

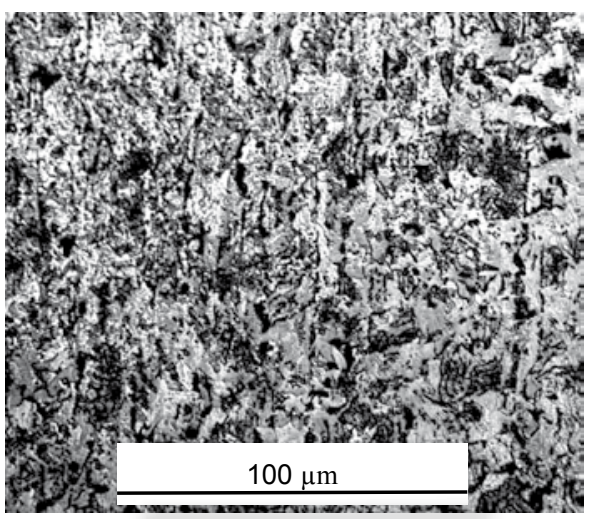

Rys. 3. Stal P265GH - struktura ferrytu z obszarami perlitu drobnopłytkowego, widoczne nieregularne obszary ferrytu oraz perlitu, lokalnie również obszary ferrytu ze sferycznymi drobnymi węglikami. Zgład metalograficzny trawiony nitalem. Pow. 1000x

Fig. 3. P265GH steel - ferritic structure of fine pearlite areas, visible irregular ferrite and pearlite areas, locally also areas with spherical ferrite fine carbides. Metallographic cross-section etched by Nital. Magn. 1000x

Tablica I. Skład chemiczny badanych stali ( $w \%$ )

Table I. Chemical composition of tested steels (in \%)

\begin{tabular}{|c|c|c|c|c|c|c|c|c|c|c|c|c|c|c|}
\hline Stal & $\mathrm{C}$ & $\mathrm{Si}$ & $\mathrm{Mn}$ & $\mathrm{P}$ & $\mathrm{S}$ & $\mathrm{Cr}$ & $\mathrm{Mo}$ & $\mathrm{Al}$ & $\mathrm{Ti}$ & $\mathrm{V}$ & $\mathrm{Nb}$ & $\mathrm{N}$ & $\mathrm{Ni}$ & $\mathrm{Cu}$ \\
\hline \multirow{2}{*}{$\mathrm{P} 265 \mathrm{GH}$} & $\leq 0,20$ & $\leq 0,40$ & $\begin{array}{c}0,80 \\
\mathrm{do} 1,40\end{array}$ & $\begin{array}{c}\max \\
0,025\end{array}$ & $\begin{array}{c}\max \\
0,015\end{array}$ & $\leq 0,30$ & $\leq 0,08$ & $\begin{array}{c}\max \\
0,020\end{array}$ & $\begin{array}{c}\max . \\
0,03\end{array}$ & $\leq 0,2$ & $\leq 0,020$ & $\leq 0,012$ & $\leq 0,30$ & $\leq 0,30$ \\
\hline \multirow{2}{*}{$\mathrm{S} 235$} & $\max$ & - & $\begin{array}{c}\max \\
0,17\end{array}$ & $\begin{array}{c}\max \\
0\end{array}$ & $\begin{array}{c}\max \\
0,40\end{array}$ & - & - & - & - & - & - & $\max$ & - & - \\
\hline
\end{tabular}




\section{Wyniki badań i ich analiza}

Analizowano podstawowe wielkości opisujące ilościowo szum Barkhausena, takie jak wartość skuteczna napięcia $U_{R M S, B N}$, energia $E_{B N}$ oraz liczba zliczeń $N_{B N}$.

Skokowe zmiany struktury domenowej przy przemagnesowywaniu powodują lokalne zaburzenia indukcji magnetycznej. Zaburzenia te są rejestrowane w cewce pomiarowej jako napięciowy szum Barkhausena. Liczba zliczeń $\mathrm{N}_{\mathrm{BN}}$ jest sumą wszystkich impulsowych zmian indukcji magnetycznej, zarejestrowanych w cewce pomiarowej jako impulsy o określonym poziomie napięcia.

a)
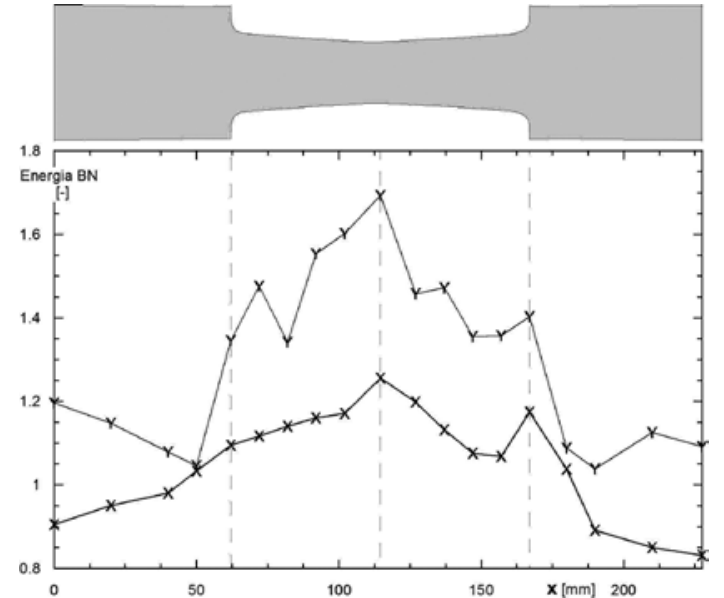

b)

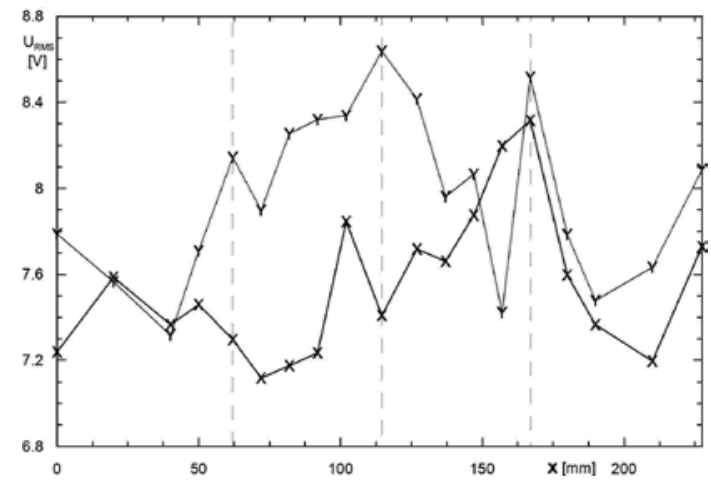

c)

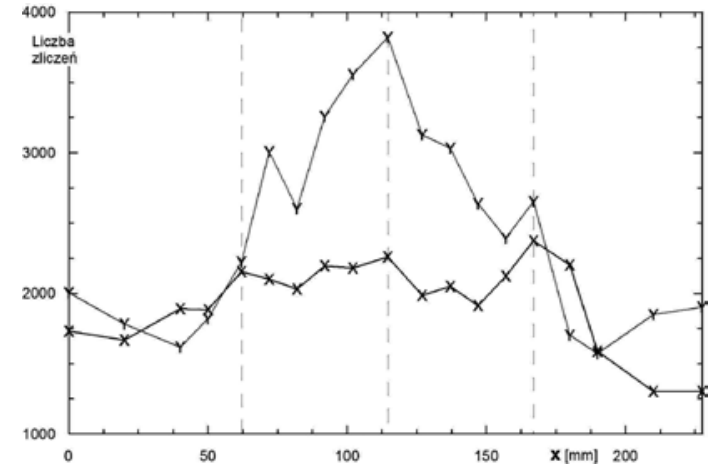

Rys. 4. Wyniki pomiarów szumu Barkhausena dla stali S235: a) rozkłady energii szumu Barkhausena $E_{B N}$, b) rozkłady maksymalnego napięcia skutecznego szumu Barkhausena $U_{\text {RMS.BN }}, C$ ) rozkłady liczby zliczeń impulsów szumu Barkhausena $\mathrm{N}_{\mathrm{BN}}$

Fig. 4. Barkhausen noise measurement results for the $\mathrm{S} 235$ a) Barkhausen noise energy distributions $E_{B N} b$ ) the distribution of the maximum of Barkhausen noise $U_{R M S, B N}, C$ ) distributions of pulse counts of Barkhausen noise $\mathrm{N}_{\mathrm{BN}}$
Energia szumu Barkhausena $\mathrm{E}_{\mathrm{BN}}$ zwana również jego intensywnością, jest zdefiniowana jako całka po czasie kwadratu napięcia impulsów $U$. Jest parametrem opisującym jedną wartością rozkład i napięcie impulsów w czasie trwania jednego cyklu przemagnesowywania T [12].

$$
E_{B N}=\int_{T} U_{i}^{2} d t
$$

Rozkłady energii $E_{B N}$, maksymalnych wartości skutecznych napięcia $U_{R M S, B N}$ oraz liczby zliczeń $N_{B N}$ przedstawiono dla stali S235 na rysunkach $4 \mathrm{a} \div 4 \mathrm{c}$, a dla stali $\mathrm{P} 265 \mathrm{GH}$ na rysunkach $5 \mathrm{a} \div 5 \mathrm{c}$.

a)
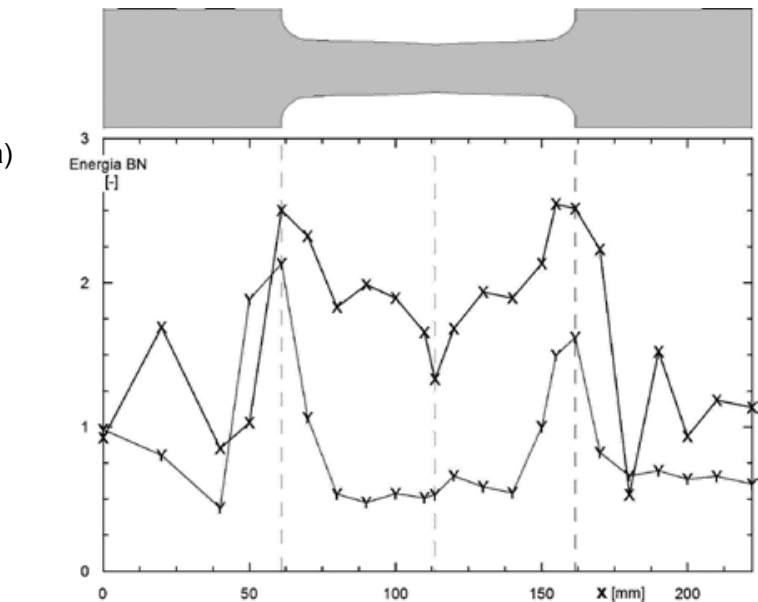

b)

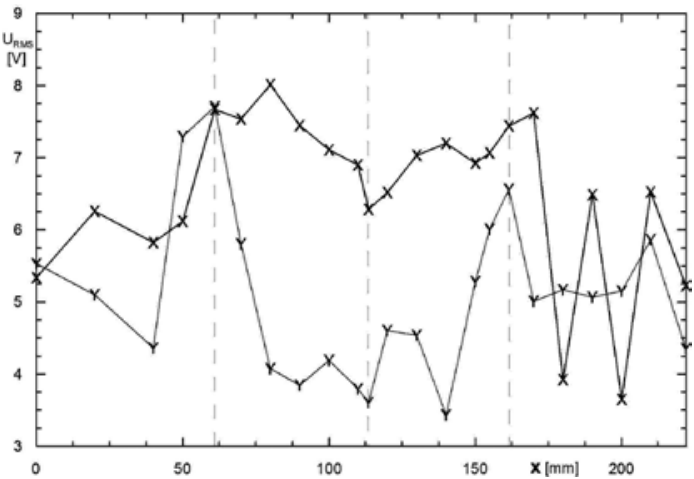

c)

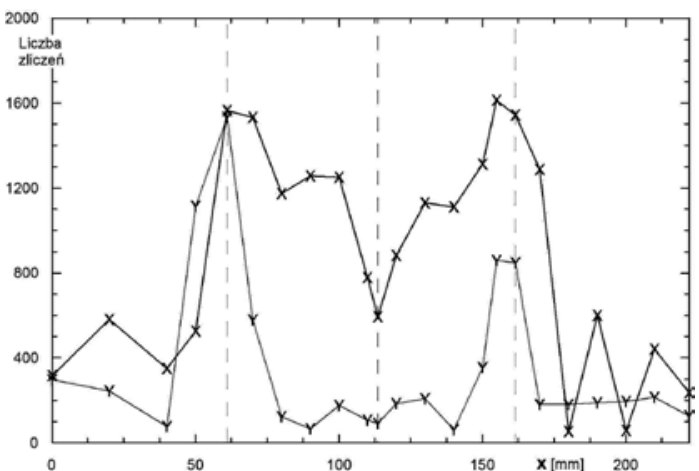

Rys. 5. Wyniki pomiarów szumu Barkhausena dla stali $\mathrm{P} 265 \mathrm{GH}$, a) rozkłady energii szumu Barkhausena $E_{B N}$, b) rozkłady maksymalnego napięcia skutecznego szumu Barkhausena $U_{R M S, B N}$, c) rozkłady liczby zliczeń impulsów szumu Barkhausena $\mathrm{N}_{\mathrm{BN}}$

Fig. 5. Barkhausen noise measurement results for steel $P 265 G H$ a) Barkhausen noise energy distributions $E_{B N} b$ ) the distribution of the maximum of Barkhausen noise $U_{R M S, B N}, C$ ) distributions of pulse counts Barkhausen noise $\mathrm{N}_{\mathrm{BN}}$ 
Analiza pomiarów WMPR obejmowała analizę rozkładów składowych WMPR oraz ich gradientów. Gradienty zmian składowych WMPR wyznaczono poprzez aproksymację odcinkową wyników pomiarów funkcjami sklejanymi 3-go stopnia. Wyniki dla stali S235 pokazano na rysunkach $6 \div 6 \mathrm{c}$, dla stali $\mathrm{P} 265 \mathrm{GH}$ na rysunkach $7 a \div 7 c$.

W tablicy II zestawiono wyniki analizy podanych wyżej wielkości w charakterystycznych strefach próbek, takich jak okolice zmiany przekroju oraz strefa szyjki. Stwierdzono, że dla obydwu badanych stali w strefach zmiany przekroju występują maksima (globalne lub lokalne) większości ( $z$ wyłączeniem niektórych składowych WMPR) analizowanych wielkości. Szyjka, czyli

a)
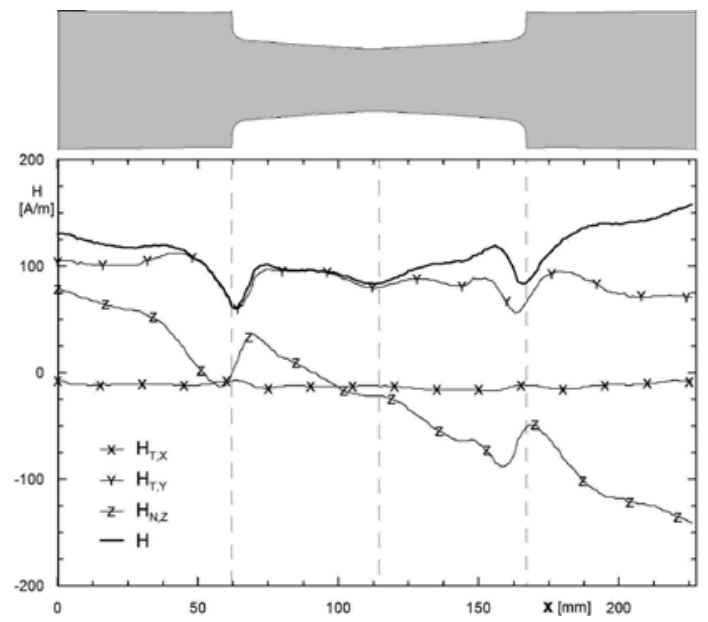

b)

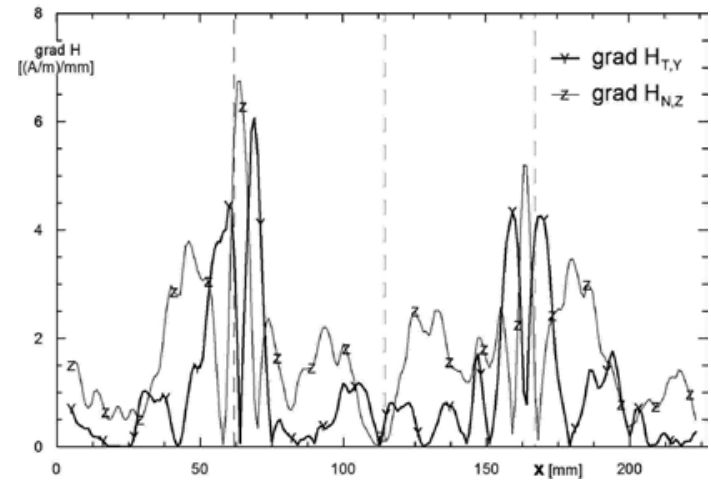

c)

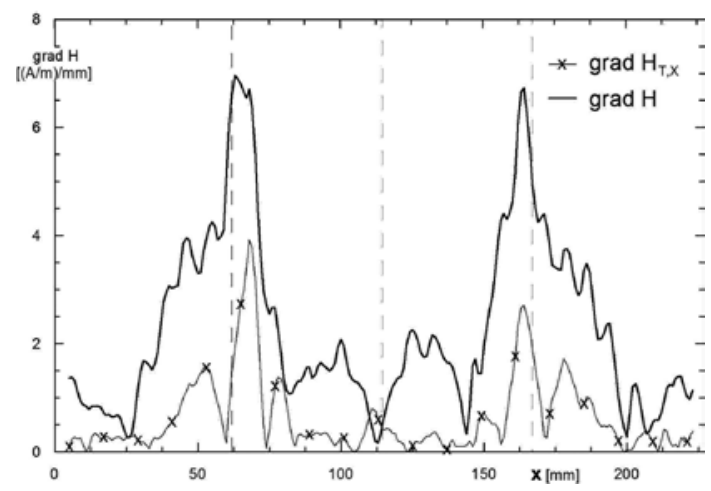

Rys. 6. Wyniki pomiarów WMPR dla próbki ze stali S235: a) rozkłady składowych WMPR, b) rozkłady gradientów $\mathrm{H}_{\mathrm{T}, \mathrm{Y}}$ oraz $\mathrm{H}_{\mathrm{N}, \mathrm{Z}}, \mathrm{c}$ ) rozkłady gradientów $\mathrm{H}_{\mathrm{TX}}$ oraz $\mathrm{H}$

Fig. 6. The WMPR measurement results for samples of S235 steel: a) the WMPR component distributions $b$ ) the distribution of gradients $\mathrm{H}_{\mathrm{T}, \mathrm{Y}}$ and $\mathrm{H}_{\mathrm{N}, \mathrm{Z}}, \mathrm{C}$ ) distribution of gradients $\mathrm{H}_{\mathrm{T}, \mathrm{X}}$ and $\mathrm{H}$ obszar lokalnego przewężenia, w którym nastạpiłoby zerwanie próbki, również wyróżnia się występowaniem globalnych lub lokalnych ekstremów rozkładów wielkości opisujących szum Barkhausena. Dla stali S235 są to maksima, natomiast dla stali P265GH minima wartości.

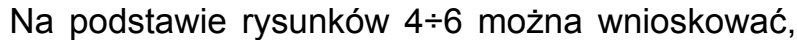
że zróżnicowanie stopnia deformacji plastycznej najlepiej oddają energia szumu Barkhausena $E_{B N}$, liczba zliczeń $\mathrm{N}_{\mathrm{BN}}$ oraz gradienty składowych WMPR. Czułość tych sygnałów diagnostycznych, zarówno wynikających z opisu ilościowego szumu Barhausena, jak i opartych na pomiarach WMPR jest zbliżona. Wcześniejsze badania wykazały że naprężenia czynne

a)

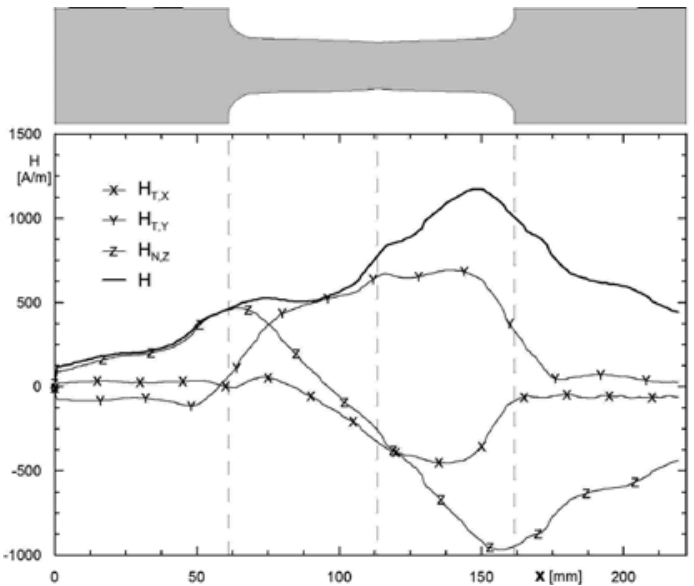

b)

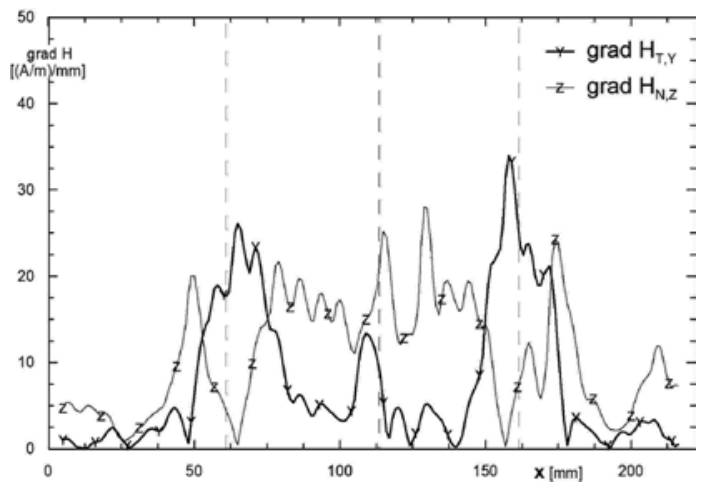

c)

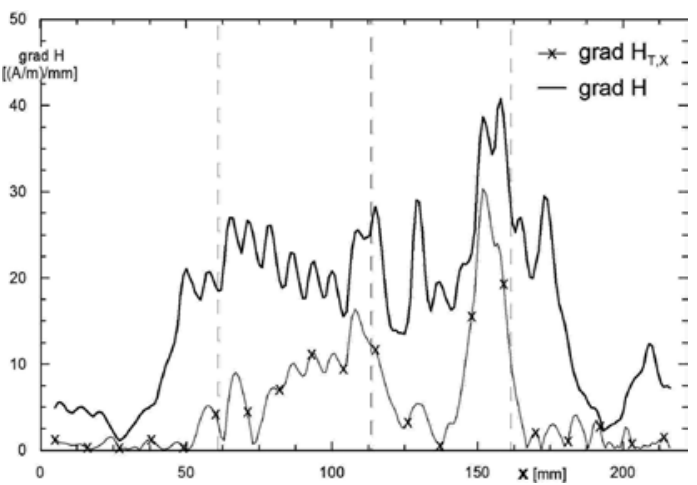

Rys. 7. Wyniki pomiarów WMPR dla próbki ze stali P265GH: a) rozkłady składowych WMPR, b) rozkłady gradientów $\mathrm{H}_{\mathrm{T}, \mathrm{Y}}$ oraz $\mathrm{H}_{\mathrm{N}, \mathrm{Z}}, \mathrm{C}$ ) rozkłady gradientów $\mathrm{H}_{\mathrm{TX}}$ oraz $\mathrm{H}$

Fig. 7. The WMPR measurement results for the sample of $P 265 \mathrm{GH}$ steel: a) the WMPR component distributions b) the distribution of gradients $\mathrm{H}_{T, Y}$ and $\mathrm{H}_{\mathrm{N}, Z}, \mathrm{c}$ ) distribution of gradients $\mathrm{H}_{\mathrm{T}, \mathrm{X}}$ and $\mathrm{H}$ 
lepiej koreluja z liczba zliczeń dla wyższych wartości napięcia progowego [13]. Natomiast relacja pomiędzy stopniem trwałej deformacji a liczbą impulsów jest zdecydowanie lepsza i występuje dla większego zakresu odkształceń oraz dla niższych napięć progowych. Możliwe jest opracowanie relacji diagnostycznych służących do oceny stopnia deformacji na podstawie wielkości. Na rysunku 8 pokazano przykładowe, opracowane w ramach badań przedstawionych w [13], zależności dla stali P265GH pomiędzy odkształceniem trwałym a liczba zliczeń - rys. 8a oraz gradientem składowej normalnej - rys. 8b.

W szumie Barkhausena obszar deformacji plastycznej charakteryzuje się wyraźną anizotropią wszystkich analizowanych wielkości. Możliwa jest również identyfikacja obszaru odkształconego plastycznie na podstawie WMPR. Najlepszym parametrem jest w tym przypadku gradient składowej normalnej, który w obszarach odkształconych plastycznie przyjmuje wyraźnie wyższe wartości.

Tablica II. Analiza symptomów diagnostycznych w charakterystycznych miejscach próbek Table II. Analysis of diagnostic symptoms in specific locations of samples

\begin{tabular}{|c|c|c|c|c|}
\hline \multirow{3}{*}{ Sygnał } & \multicolumn{4}{|c|}{ Miejsce występowania w stali } \\
\hline & \multicolumn{2}{|c|}{ S235 } & \multicolumn{2}{|c|}{ P265GH } \\
\hline & szyjka & zmiana przekroju & szyjka & zmiana przekroju \\
\hline Energia BN & $\begin{array}{l}X-\text { maksimum } \\
Y-\text { maksimum }\end{array}$ & $\begin{array}{l}X \text { - lokalne maksimum } \\
Y \text { - lokalne maksimum }\end{array}$ & $\begin{array}{l}X \text { - lokalne minimum } \\
Y \text { - brak }\end{array}$ & $\begin{array}{l}X-\text { maksimum } \\
Y-\text { maksimum }\end{array}$ \\
\hline $\mathrm{U}_{\mathrm{RMS}, \mathrm{BN}}$ & $\begin{array}{l}X \text { - lokalne minimum } \\
Y \text { - maksimum }\end{array}$ & $\begin{array}{l}X \text { - lokalne maksimum } \\
Y \text { - lokalne maksimum }\end{array}$ & $\begin{array}{l}X \text { - lokalne minimum } \\
Y \text { - lokalne minimum }\end{array}$ & $\begin{array}{l}X-\text { maksimum } \\
Y-\text { maksimum }\end{array}$ \\
\hline Liczba zliczeń & $\begin{array}{l}X \text { - lokalne maksimum (małe) } \\
Y \text { - maksimum }\end{array}$ & $\begin{array}{l}X \text { - maksimum } \\
Y \text { - lokalne maksimum }\end{array}$ & $\begin{array}{l}X-\text { lokalne minimum } \\
Y-\text { lokalne minimum } \\
\text { (niewielkie) }\end{array}$ & $\begin{array}{l}X-\text { maksimum } \\
Y-\text { maksimum }\end{array}$ \\
\hline $\mathrm{H}$ & $\begin{array}{l}\text { zauważalna zmiana trendu } \\
\text { składowych } \mathrm{H}_{\mathrm{T}, \mathrm{Y}} \mathrm{i}_{\mathrm{N}, \mathrm{z}}\end{array}$ & $\begin{array}{l}\text { wyraźne lokalne zaburzenie - } \\
\text { ekstrema wartości }\end{array}$ & $\begin{array}{l}\text { zauważalna zmiana trendu } \\
\text { składowych } \mathrm{H}_{\mathrm{T}, \mathrm{Y}} \mathrm{i} \mathrm{H}_{\mathrm{N}, \mathrm{Z}}\end{array}$ & $\begin{array}{l}\text { wyraźne lokalne zaburzenie - } \\
\text { ekstrema wartości }\end{array}$ \\
\hline Grad H & $\begin{array}{l}\text { grad } \mathrm{H}_{\mathrm{T}, \mathrm{X}}-\text { lokalne maksimum } \\
\text { grad } \mathrm{H}_{\mathrm{T}, \mathrm{Y}} \text { oraz grad } \mathrm{H}_{\mathrm{N}, \mathrm{Z}}-\text { war- } \\
\text { tości zbliżone do zera }\end{array}$ & $\begin{array}{l}\text { maksimum wszystkich } \\
\text { gradientów }\end{array}$ & $\begin{array}{l}\text { lokalne maksima wszystkich } \\
\text { gradientów }\end{array}$ & $\begin{array}{l}\text { grad } \mathrm{H}_{\mathrm{T},}, \text { grad } \mathrm{H}_{\mathrm{N}, \mathrm{Z}}-\text { lokalne } \\
\text { maksimum } \\
\text { grad } \mathrm{H}_{\mathrm{T}, \mathrm{Y}}-\text { maksimum }\end{array}$ \\
\hline
\end{tabular}

a)

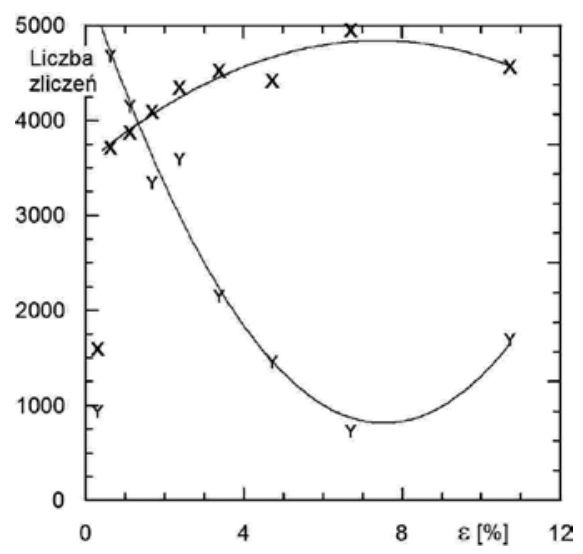

b)

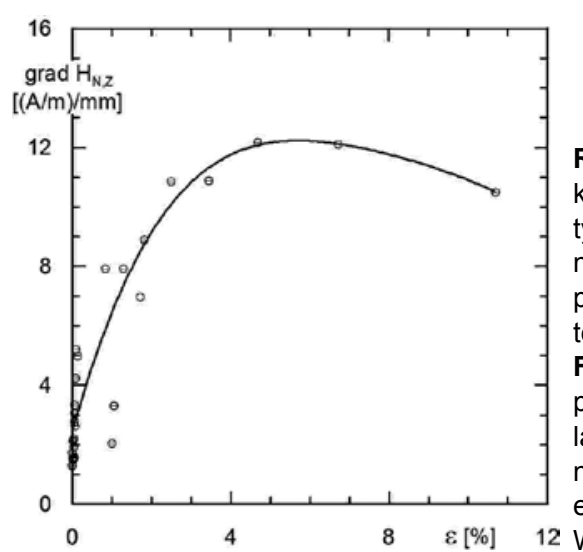

Rys. 8. Przykładowe zależności pomiędzy odkształceniem trwałym a parametrami magnetycznymi: a) zależność pomiędzy odkształceniem trwałym $\varepsilon$ a liczbą zliczeń $\mathrm{N}_{\mathrm{BN}}$, b) zależność pomiędzy odkształceniem trwałym $\varepsilon$ a gradientem składowej normalnej WMPR

Fig. 8. Example of the relationship between the permanent set and magnetic parameters: a) relationship between permanent strain $\varepsilon$ and the number of counts $\mathrm{N}_{\mathrm{BN}}$, b) the relationship between permanent strain $\varepsilon$ a normal component of the WMPR gradient

\section{Podsumowanie}

Przedstawiono wyniki pomiarów szumu Barkhausena i własnego magnetycznego pola rozproszenia WMPR w próbkach odkształconych plastycznie. Porównano rozkłady wielkości ilościowo opisujących szum Barkhausena i WMPR. Stwierdzono, że zróżnicowanie stopnia deformacji plastycznej dobrze oddają: energia szumu Barkhausena $\mathrm{E}_{\mathrm{BN}}$, liczba zliczeń $\mathrm{N}_{\mathrm{BN}}$ oraz gradienty składowych WMPR. Czułość tych sygnałów diagnostycznych jest zbliżona. Możliwe jest opracowanie ilościowych relacji diagnostycznych służących do oceny stopnia deformacji na podstawie ww. wielkości. Opracowanie rzetelnych relacji diagnostycznych wymaga rozwiązania wielu problemów metrologicznych. Sa one związane z kształtem i wielkością elementu, stanem warstwy wierzchniej, strukturą oraz ogólnym stanem namagnesowania $[13,14]$. 


\section{Literatura}

[1] Jiles D.C.: Theory of the magnetomechanical effect, J. Phys D: Appl. Phys., 28 (1995) s. 1537-1546.

[2] Deputat J.: Podstawy metody magnetycznej pamięci metalu. Dozór Techniczny 5/2002 s. 97-105.

[3] Dubow A.A.: Principal features of metal magnetic memory method and inspection tools as compared to known magnetic NDT methods. WCNDT 2004, Montreal Canada, http://www. ndt.net/article/wcndt2004/papers/359.ntm.

[4] Roskosz M. Gawrilenko P.: Analysis of changes in residual magnetic field in loaded notched samples, NDT\&E International 41 (2008) s. 570-576.

[5] Roskosz M.: Wpływ naprężeń czynnych i resztkowych na własne pole magnetyczne ferromagnetyków, Przegląd Spawalnictwa 13/2011, s. 46-49.

[6] Roskosz M., Bieniek M.: Evaluation of residual stress in ferromagnetic steels based on residual magnetic field measurements NDT\&E International 45 (2012), s. 55-62.

[7] Roskosz M.: Feasibility of Stress State Assessment on the Grounds of Measurements of the Residual Magnetic Field Strength of Ferromagnetics, Electromagnetic Nondestructive Evaluation (XIV). Chady T., Gratkowski S., Takagi T., Udpa S., (Eds Studies in Applied Electromagnetics and Mechanics 35, IOS Press, 2011, s. 339-47.

[8] Żurek Z.H.: Magnetic contactless detection of stress distribution and assembly defects in constructional steel element, NDT\&E International 38 (2005) s. 589-595.
[9] Mierczak L.L., Jiles D.C., Fantoni G.: A New Method for Evaluation of Mechanical Stress Using the Reciprocal Amplitude of Magnetic Barkhausen Noise IEEE Transactions on Magnetics, VOL. 47, No. 2, 2011, s. 459-65.

[10] Piotrowski L., Augustyniak B., Chmielewski M, Tomáš I.: The influence of plastic deformation on the magnetoelastic properties of the CSN12021 grade steel, Journal of Magnetism and Magnetic Materials 321 (2009) 2331-2335

[11] Stupakov O., Takagi T., Uchimoto T.: Alternative magnetic parameters for characterization of plastic tension, NDT\&E International 43 (2010), s. 671-676.

[12] White S., Krause T., Clapham L.: Quantitative analysis of surface Barkhausen noise measurements, Review of Quantitative Nondestructive Evaluation. Vol. 27, ed. by D.O. Thompson and D. E. Chiment, 2008 American Institute of Physics.

[13] Roskosz M., Fryczowski K.: Możliwości wykorzystania zmian właściwości magnetycznych do oceny stanu wytężenia stali kotłowych na przykładzie stali P265GH, 4 Konferencja Naukowo-Techniczna "Diagnostyka Materiałów i Urządzeń Technicznych", Gdańsk 2012.

[14] Roskosz M., Bieniek M.: Opracowanie i weryfikacja metody oceny naprężeń resztkowych i-rzędu dla próbek ze stali kotłowej 16Mo3, 4 Konferencja Naukowo-Techniczna „Diagnostyka Materiałów i Urządzeń Technicznych”, Gdańsk 2012.

\section{W następnym numerze}

Andrzej Oneksiak, Tadeusz Sarnowski, Paweł Cegielski, Andrzej Kolasa, Dariusz Golański

Transfer innowacyjnych rozwiązań konstrukcyjnych w przemysłowych urządzeniach do automatyzacji procesów spawalniczych

\section{Jarosław Grześ}

Wymiar fraktalny gradientowej warstwy pośredniej $\mathrm{Al}_{2} \mathrm{O}_{3}-\mathrm{Cr}$

\section{Zbigniew Mirski, Dawid Majewski}

Lutowność tytanu w warunkach płomieniowego lutowania twardego pod osłoną topnika

\section{J. Zimmerman, D. Golański, T. Chmielewski, W. Włosiński}

Model obliczeniowy do analizy naprężeń własnych w układzie powłoka-podłoże podczas nanoszenia powłok metodami termicznymi

Krzysztof Skrzyniecki, Cegielski Paweł, Andrzej Kolasa, Paweł Kołodziejczak

Charakterystyki statyczne nowoczesnych urządzeń do spawania łukowego

Marcin Winnicki, Aleksandra Małachowska, Andrzej Ambroziak

Badania numeryczne tworzenia metodą LPCS powłoki z cyny na podłożu aluminiowym 